\title{
Erratum to: Europe as a Stronger Global Actor
}

\author{
Simon Duke
}

(C) The Editor(s) (if applicable) and The Author(s) 2017

S. Duke, Europe as a Stronger Global Actor, European

Administrative Governance, DOI 10.1057/978-1-349-94945-8

\section{DOI 10.1057/978-1-349-94945-8}

The original version of this book contained an error which has now been corrected. The correction is given below:

The references for the chapters were inadvertently missed, these have now been added.

The updated online version of this book can be found at DOI 10.1057/978-1-349-94945-8

(C) The Editor(s) (if applicable) and The Author(s) 2017 